\title{
Redes Informales e Instituciones Democráticas en América Latina*
}

\author{
Aldo Mascareño ${ }^{1}$ \\ Artur Stamford da Silva ${ }^{2}$ \\ Daniel Loewe ${ }^{1}$ \\ Darío Rodríguez \\ ${ }^{1}$ Universidad Adolfo Ibáñez (UAI), Santiago, Chile. E-mail: aldo.mascareno@uai.cl \\ ${ }^{2}$ Universidade Federal de Pernambuco (UFPe), Recife, PE, Brasil. \\ ${ }^{3}$ Universidad Diego Portales, Santiago, Chile.
}

\section{INTRODUCCIÓN}

nel ideario normativo de la modernidad, los derechos fundamenE tales juegan un papel central. En un sentido abstracto, ellos se expresan en conceptos como derecho a la vida, libertad, igualdad, dignidad, propiedad, participación, y en derivaciones de ellos aplicadas a campos diversos de actividad social, como derecho a un medioambiente sano, libertad de expresión, libertad de elección, libertad de culto, igualdad de trato, igualdad ante la ley, participación política, participación social, participación en el mundo laboral (Mascareño y Araujo, 2012; Vrdoljak, 2013; Bringel y Domingues, 2015). En un sentido concreto, estos derechos pueden expresarse como un concepto formal que enfatiza su carácter positivo plasmándose en constituciones nacionales -, un concepto sustantivo - que los sitúa en el ámbito de los derechos humanos positivizados -, o un concepto procedimental - que refleja sus dificultades de institucionalización democrática en la

\footnotetext{
* Agradecemos a los revisores anónimos de DADOS - Revista de Ciências Sociais por sus comentarios al texto. Este artículo ha sido realizado con el apoyo de los proyectos del Fondo Nacional de Desarrollo Científico y Tecnológico (Fondecyt) 1130406 y 1140344 (Comisión Nacional de Investigación Científica y Tecnológica - Conicyt, Chile), del Núcleo Milenio Modelos de Crisis (NS130017) y del Conselho Nacional de Desenvolvimento Científico e Tecnológico (CNPq), Brasil.
}

DADOS - Revista de Ciências Sociais, Rio de Janeiro, vol. 59, no-3, 2016, pp. 683 a 718. 
transformación de derechos humanos en derecho positivo (Alexy, 2006).

Esta forma de concebir el rol de los derechos fundamentales en la modernidad establece una relación inmanente, cooriginaria y coevolutiva, entre la formación e institucionalización de los derechos fundamentales y la emergencia de la modernidad. La argumentación puede adquirir diversos énfasis conceptuales (Alexy, 1983; Habermas, 1998; Luhmann, 1999; Kelsen, 2005; Teubner, 2012; Neves, 2013; Kjaer, 2014). No obstante, la relación coproductiva entre modernidad y derechos fundamentales se sostiene en sus aspectos básicos.

Cuando, sin embargo, se constata que en una región como América Latina las condiciones de desigualdad, inequidad, pobreza y exclusión individual y grupal de múltiples rendimientos institucionales implican a la vez un debilitamiento de los derechos fundamentales, se pone entonces en duda la extensión y profundidad de la modernidad en América Latina en cuanto orden social promovido y sustentado en ellos (Neves, 2007; Domingues, 2008; Mascareño, 2010, 2012). Puesto en términos de una correlación: a mayor desigualdad (económica, educativa, de inclusión política, jurídica, de ejercicio de libertades), menor concretización de derechos fundamentales (de equidad, igualdad, participación, libertad).

Esto puede mirarse desde dos perspectivas. En la primera, el acento se pone en la debilidad de los marcos institucionales democráticos en América Latina para absorber las crecientes demandas de institucionalización de los públicos y el aumento cuantitativo de ellos (Germani, 1981; Garretón, 1983; Lechner, 2001; Neves, 2007). En la segunda, sin necesariamente descartar lo anterior, se podría suponer que en América Latina el tipo de instituciones democráticas que promueven los derechos fundamentales (individualización, universalismo normativo, división del trabajo, diferenciación funcional, Estado de derecho, democracia política) puede cooperar, pero también competir con u oponerse a formas alternativas de organización social estructuradas en torno a redes informales (Lomnitz, 1977, 1993; Rodríguez, 2004; Bringel, 2010, 2012; Mascareño, 2010, 2012; Groppa y Hoevel, 2014).

La hipótesis de este artículo es que en el contexto latinoamericano es posible identificar analíticamente, y desde un punto de vista sociológi$\mathrm{co}$, tres tipos de redes informales que denominamos redes paraformales, redes de corrupción y redes de criminalidad. Empleamos el concepto de re- 
des informales como una categoría general de relaciones sociales acopladas de manera suelta (Weick, 1976) y que, por medio de diferenciaciones internas, se relacionan con las instituciones democráticas de modos distintos:

a) Las redes paraformales producen una relación de integración con las instituciones democráticas. Son paraformales en el sentido de que, siendo informales, están junto a instituciones formales con las cuales coevolucionan y se integran de manera sinérgica. Contribuyen al funcionamiento reflexivo de estas instituciones (incluso en relación de oposición) alertando sobre sus debilidades y evaluando permanentemente sus rendimientos en cuanto formas de realización de derechos fundamentales o humanos. Ellas son un elemento constitutivo del orden democrático y, por tanto, son indispensables para el funcionamiento reflexivo de las instituciones modernas. Se trata de movimientos sociales, de protestas, comunidades epistémicas y agrupaciones políticas, comunitarias o de públicos, las que de manera legítima llaman la atención sobre los vacíos de las instituciones democráticas o complementan sus operaciones.

b) Las redes de corrupción, a su vez, se superponen a las instituciones democráticas. Estas redes se constituyen como estructuras parasitarias que intervienen en el funcionamiento autónomo de las instituciones democráticas, utilizan los rendimientos de esas instituciones en su propio beneficio y dificultan la concretización equitativa de los derechos fundamentales. Se trata, por ejemplo, de formas de corrupción privado-pública, de redes entre delincuentes y policía, de favores y privilegios de acceso a instancias públicas, que se instalan sobre estructuras democráticas, se ocultan en ellas y obtienen rendimientos de manera ilegítima.

c) Por su parte, las redes de criminalidad producen un desacoplamiento de las instituciones democráticas y establecen un predominio en un espacio social determinado. Con ello acontece una suspensión mayor (aunque no absoluta) de los derechos fundamentales propios del ordenamiento democrático y, en su lugar, se activan estructuras normativas de carácter particularista que se oponen, generalmente de manera violenta, al orden democrático. Ejemplos de esto son las redes de narcotráfico y crimen organizado.

En este artículo buscamos desarrollar y demostrar la validez de un modelo conceptual de base sociológica acerca de los distintos tipos de re- 
lación que las redes informales pueden establecer con instituciones democráticas y su acción - cooperativa o conflictiva - sobre la concretización de derechos fundamentales. En general, la aproximación a la relación entre redes e instituciones democráticas adquiere un tono más bien dualista. Holzer (2006), por ejemplo, establece una diferencia entre redes de simpatía (integradas con instituciones democráticas) y aquellas que más bien se oponen a ellas. Para dar cuenta del mismo fenómeno, Ledeneva (2013) habla de redes solidarias y subversivas. Lomnitz (1977), aun cuando su énfasis está en la reciprocidad de las redes, también las distingue de la situación de compadrazgo. De modo similar, Corrochano (2002), entre otros, distingue entre redes asociativas y las formas más voraces de las redes clientelares. Auyero (2012) sugiere igualmente que las redes clientelares operan como dominación política, pero también como protección genuina de los pobres. Incluso Bourdieu (2005), en sus análisis de la formación del Estado moderno, distingue entre formas de relación basadas en el principio jurídico de carácter universalista de aquellas basadas en el principio dinástico que privilegian "la casa".

Con nuestro modelo conceptual pretendemos aportar una visión integrada de estas relaciones en un esquema analítico que logre identificar situaciones sociales distintas haciéndolas comparables por medio de la aplicación de un conjunto integrado de categorías de observación. Para esto, introducimos una perspectiva sociológica que considera el espacio social en el que la relación entre redes e instituciones democráticas tiene lugar, sus formas de coordinación social y sus características normativas. Con ello complementamos la observación de la ciencia política, generalmente de énfasis institucional (Helmke y Levitsky, 2006), acerca de estas relaciones. Metodológicamente, empleamos casos paradigmáticos descritos en la amplia literatura empírica sobre el tema en América Latina y agregamos casos adicionales que permiten complementar la propuesta conceptual. Esto nos permite discutir el aporte sociológico del esquema conceptual con algunas de las investigaciones centrales sobre el tema en América Latina.

El artículo se estructura del modo siguiente. En la primera sección desplegamos los fundamentos del esquema analítico que proponemos y desarrollamos discusiones con la literatura teórica sobre redes informales. Fundamentalmente, proponemos aquí tres tipos de relación entre redes e instituciones democráticas: la integración, la superposición y el desacoplamiento. En la segunda sección ilustramos estas formas de relación con tres casos principales y otros secundarios extraídos de 
la literatura especializada. Con los primeros mostramos un caso paradigmático que instruye la formulación conceptual y desde el cual puede derivarse también la plausibilidad de la relación particular entre redes e instituciones democráticas; con los segundos mostramos variaciones para enriquecer la formulación conceptual cuando ello se requiere. Ya en la tercera sección discutimos los hallazgos y establecemos nuevas relaciones con la literatura sobre el tema. Finalmente, en la cuarta sección elaboramos las conclusiones y volvemos sobre el aporte central del artículo.

\section{HACIA UNA TEORÍA DE LA RELACIÓN ENTRE REDES INFORMALES E INSTITUCIONES DEMOCRÁTICAS EN AMÉRICA LATINA}

Desde una construcción típico-ideal, es posible distinguir, tal como se puede observar de forma esquemática en el Cuadro 1, tres formas de relación entre redes e instituciones democráticas en América Latina: la integración de ambas, su superposición y su desacoplamiento.

Cuadro 1

Formas de Relación entre Redes Informales e Instituciones Democráticas

\begin{tabular}{|l|c|c|c|}
\hline Tipo principal & Integración & Superposición & Desacoplamiento \\
\hline Concepción de espacio & Relacional & $\begin{array}{c}\text { Limitadamente re- } \\
\text { lacional }\end{array}$ & Contenedor \\
dad
\end{tabular}

Fuente: Elaboración propia.

Teniendo en cuenta estas modalidades de relación, explicaremos enseguida sistemáticamente cada una de ellas, teniendo en cuenta su concepción de espacio, su forma de coordinación y su referencia normativa. Para ello, vinculamos nuestras proposiciones fundamentalmente con literatura teórica sobre el tema.

\section{La Integración de Redes Paraformales e Instituciones Democráticas}

Una integración de lo que denominamos redes paraformales e instituciones democráticas tiene lugar si ambas dimensiones se fomentan 
recíprocamente y desarrollan relaciones productivas. Boris Holzer (2006:9 y ss.) alude aquí a "redes de simpatía" basadas en la confianza. Alena Ledeneva (2013) habla de la dimensión solidaria de las redes, mientras Putnam (1993:177) traduce esto en términos de capital social: "Círculos virtuosos resultan en un equilibrio social con altos niveles de cooperación, confianza, reciprocidad, compromiso cívico y bienestar colectivo". Ejemplos de esta integración de redes informales e instituciones democráticas son la influencia de la amistad en los negocios, la colegialidad en el trabajo académico o la procedencia cultural para la pertenencia a organizaciones familiares de todo tipo. También puede mencionarse aquí la relación entre política y movimientos sociales (Bringel, 2010), en particular si se trata de un mejoramiento de las condiciones de vida generales reclamado por los movimientos sociales. En esta modalidad de relación, las redes informales contribuyen a eliminar determinados costes de transacción de la coordinación, de manera que las operaciones formales puedan efectuarse con mayor fluidez en un entorno con complejidad reducida (Luhmann, 2000a).

Para esta forma de integración de redes informales e instituciones democráticas, la concepción de espacio es de tipo relacional, es decir, los actores sociales (sea operen en contextos formales o informales) constituyen y construyen tales espacios en una continua interacción (Schroer, 2006). En un espacio concebido de esta manera, redes e instituciones operan con objetivos paralelos pero complementarios: el trabajo científico en equipo fortalece, por ejemplo, la colegialidad e incluso la amistad entre científicos, y produce, a la vez, nuevo conocimiento científico (Knorr-Cetina, 1981; Latour y Woolgar, 1986). Las redes que vinculan estas dimensiones ofrecen una solución de continuidad: relaciones personales o grupales funcionan de manera sinérgica con la operación de instituciones democráticas más formalizadas. Los movimientos sociales y de protesta funcionan bajo esta modalidad de integración. Operacionalmente, ellos tienen una función reflexiva en relación con las instituciones democráticas: por medio de sus demandas alertan sobre riesgos, peligros y debilidades de la estructura institucional (Luhmann, 1996). Normativamente, su función es indicar a las mismas estructuras institucionales dónde y por qué los compromisos de valor adquiridos institucionalmente no están siendo realizados adecuadamente (Parsons, 1968). Con ello, los movimientos sociales mejoran la calidad de la información, amplían su diversidad y promueven la incorporación de nuevos objetivos en la agenda política (Bringel y Echart, 2008; Gohn y Bringel, 2013). 
La modalidad fundamental de coordinación social opera bajo el principio de la inclusión plena (Stichweh, 2005). Inclusión plena significa que la norma de acceso a las instituciones o sistemas sociales no puede estar sujeta a ninguna limitación referida a las personas: no hay, en principio, motivos de exclusión para la participación de las personas en los distintos roles de una sociedad diferenciada. Este es justamente el tipo de orden social que promueven los derechos fundamentales.

Puesto que en las relaciones de integración entre redes informales e instituciones democráticas se trata, al menos inicialmente, de una relación sinérgica, la referencia normativa dominante es el universalismo posconvencional. Postconvencionalidad implica la orientación de la conducta por medio de principios reflexivos - dignidad, libertad, libertad de comunicación, derecho a voto, igualdad ante la ley - que demandan validez para todo individuo (Habermas, 1998). Los derechos fundamentales institucionalizan estos principios (los sostienen estructural y simbólicamente) al positivizarlos como comunicación jurídica (Luhmann, 1999). Las redes paraformales operan aquí con la finalidad de apoyar este ordenamiento. Puesto que estos principios posconvencionales son de carácter universal, la normatividad de las redes paraformales promueve inclusión universal para todos los afectados por un determinado problema social (Habermas, 1998). Incluso movimientos étnicos que apelan a reivindicaciones de tipo comunitario contribuyen a la transformación de aspiraciones normativas en derecho positivo, tanto en términos de políticas públicas como de derechos constitucionales, con lo que favorecen a otros grupos o personas en situaciones de desigualdad similar.

\section{La Superposición de Redes de Corrupción e Instituciones Democráticas}

Una relación de superposición tiene lugar si las redes informales, en forma de redes de corrupción, intervienen en las instituciones democráticas haciendo uso parasitario de sus rendimientos y ocultándose tras una fachada de procedimentalidad. Se pasa desde la dimensión solidaria a la dimensión subversiva de la redes (Ledeneva, 2013). Ejemplos de este tipo de superposición son la corrupción basada en el dinero, los favores en la esfera pública (Auyero, 1999, 2012), y la formación de redes delincuenciales (Uslaner, 2008). En su expresión más extrema se trata de agrupaciones que desarrollan actividades al margen de la legalidad 
y redes en el aparato público orientadas a la obtención de beneficios privados por medio de corrupción (Carnevali, 2014).

En esta modalidad de relación, la concepción de espacio es, al igual que en las formas de integración, de tipo relacional, es decir, construida por los actores. Pero en este caso la posibilidad de participar en el espacio de las relaciones está limitada por la pertenencia a una red que cuida sus límites porque de ello dependen los réditos que obtiene. Las investigaciones de Javier Auyero sobre redes clientelares del peronismo argentino muestran la construcción de este tipo de espacialidad social entre los círculos internos y los más amplios que se conforman en torno a los brokers. Como lo afirma Auyero (1999:323), especialmente quienes se encuentran en los círculos internos "son cooptados por las prácticas institucionalizadas del clientelismo, y de este modo toman parte en la reproducción de las relaciones jerárquicas dentro del campo político local y dentro del espacio de la villa". Las redes de favores, de tráfico de influencias, así como las colusiones de mercado o las redes de corrupción, no se pueden ampliar a todos ni ser públicas. Deben ser restrictivas en sus formas de inclusión y exclusión. En la medida en que se es parte de ellas, se puede construir el espacio social relacional. Sin embargo, puesto que en estos casos la red funciona en estratos (distintos niveles de operación, círculos internos y amplios), los estratos externos tienen una menor capacidad de coconstruir el espacio social que los estratos internos de la red. Esta forma de concebir el espacio es, de tal modo, la antesala de la concepción de espacio como contenedor (Schroer, 2006).

En cuanto a la coordinación social, la inclusión y la exclusión se hacen selectivas: se favorece la inclusión de los miembros de la red y se desfavorece la de los no miembros, lo que no excluye relaciones de compromiso genuinas y profundas entre los brokers y "sus gentes" (Auyero, 1999:324). Los participantes de la red clientelar logran acceder a rendimientos institucionales de manera no sancionada legítimamente y, con esto, intervienen en la autonomía y la neutralidad de contextos fundados en tales regulaciones. Las reglas formales funcionan como si. En cierto modo, se mantienen "simulando legalidad" (Luhmann, 2002:137), mientras que en el trasfondo domina el partidismo y la mantención del secreto (Simmel, 1992). Especialmente en redes de corrupción, esta falta de transparencia es la condición para una intervención exitosa de las reglas procedimentales de las instituciones democráticas. Por eso, las redes se esfuerzan en eliminar las huellas de sus pro- 
pias operaciones: el soborno se oculta tras la fachada de un procedimiento legal, el parentesco se convierte en la calificación técnica de una persona para un puesto, la reputación se desvía hacia las ventajas de la popularidad de una persona, y la coacción es utilizada como estrategia de supervivencia y, en el mejor de los casos, como forma de lobby (Mascareño, 2012). Dada la condición de mantención del secreto, se tiene que saber con quién se puede hablar sobre las prestaciones y las exigencias de la red, de lo contrario se corre el riesgo de poner al descubierto el particularismo de la red y, eventualmente, perder posibilidades de beneficio y exponerse a sanciones negativas. Entonces, las redes de este tipo tienen que controlar constantemente sus límites sociales (¿con quién puede uno comunicarse?), factuales (¿sobre qué puede uno comunicar?) y temporales (¿cuándo precisamente y por cuánto tiempo puede uno comunicar?).

Con relación a su carácter normativo, dado que se trata aquí de inclusión y exclusión selectiva, se forma una estructura particularista con normas propias para el grupo de participantes, al que este responde convencionalmente (por adecuación a las normas del propio grupo). En este caso se trata de círculos de lealtad que justifican favorecer e incluir a cercanos y excluir a otros con los cuales no se genera (o no se requiere) un vínculo de lealtad (Loewe, 2010). Puesto que se trata de superposición de redes clientelares o de corrupción e instituciones democráticas, las normas convencionales de las redes (creadas para la defensa de los intereses propios de los participantes de la red) colisionan con las normas de instituciones de inclusión universal que operan bajo el principio posconvencional de inclusión plena sustentado en derechos fundamentales. En tales casos, se puede mantener la expectativa de un orden social promovido por los derechos fundamentales, pero la intervención que produce la red informal introduce distorsiones en ese orden que favorecen a los miembros de la red.

\section{El Desacoplamiento de Redes Criminales e Instituciones Democráticas}

El desacoplamiento de redes e instituciones democráticas aparece en el caso de redes criminales. Se trata aquí de una tendencia a la separación de espacios sociales en la que, de todos modos, cada uno entiende al otro de manera antagónica. Los mecanismos informales se desligan de los supuestos del derecho y de los derechos fundamentales. El poder, por ejemplo, no funciona como amenaza jurídicamente controlada de 
uso de la fuerza; se desacopla del control jurídico y actúa sobre los cuerpos como violencia y amenaza continua sobre la vida (Luhmann, 2005a). Los carteles territoriales de droga y también el crimen organizado en determinados barrios de la ciudad son ejemplos de ello. La clave en estos casos es que, en un espacio socioterritorial definido en el que, paralelamente, las instituciones del Estado de derecho se retiran o renuncian a su acción sobre esos territorios (Deffner, 2007, 2011), las redes actúan con una cierta soberanía o introducen un tipo de intervención violenta también contraria a los derechos fundamentales (Feltran, 2012). Estas instituciones no pueden enfrentar las consecuencias de su propia negligencia (violencia, corrupción, pobreza extrema) y fracaso en construir un orden social basado en derechos fundamentales. Paralelamente y por esto, en tales espacios, las redes de criminalidad también logran una alta institucionalización.

Al contrario de las anteriores, en esta modalidad de relación prima la concepción de espacio como contenedor (Schroer, 2006): el territorio es un espacio que contiene relaciones sociales en las que predomina la amenaza de la vida. En este sentido, el espacio como contenedor se transforma en una zona de exclusión (Luhmann, 2005a) cuando se le observa desde la perspectiva de la inclusión plena que los derechos fundamentales promueven. En tal zona de exclusión, los derechos fundamentales quedan marginalmente situados como exterior, como expectativa de inclusión de otros.

En la modalidad de desacoplamiento, la inclusión y exclusión se hacen coactivas y se ejercen como control conductual sobre los cuerpos. Control del cuerpo significa una limitación coercitiva del margen de maniobra individual para poder manejar las expectativas de comportamiento y, con ello, las formas de inclusión y exclusión. Esto supone una conexión fáctica de motivación y acción mediante mecanismos simbióticos como la violencia o la percepción (Luhmann, 2005b). El control es realizado a través de grupos que monopolizan los mecanismos de aplicación directa de la violencia, de manera que la conducta, en la mayoría de los casos, apunta a la sobrevivencia, ya sea como protección del cuerpo y la vida o como satisfacción de necesidades.

El control coactivo se asocia a una forma preconvencional de normatividad particularista de grupo como premio y castigo, en el que se premian las muestras de lealtad y se castigan los comportamientos desleales. Esto es lo que Arias y Rodrigues (2006) denominan mito de la 
seguridad personal, o lo que Feltran (2008:93) ha llamado "mundo del crimen": "un conjunto de códigos y sociabilidades establecidas, prioritariamente en el ámbito local en torno a negocios ilícitos del narcotráfico, de robos y hurtos". Por medio de estas formas de normatividad, los individuos pueden sentirse seguros si generan lazos con grupos (redes criminales y narcotraficantes) que monopolizan la aplicación de la violencia. Puesto que las orientaciones normativas del Estado de derecho formuladas en derechos fundamentales tienen aquí una relevancia marginal o nula, estos espacios pueden entenderse paradójicamente como negación moderna de la modernidad.

\section{MODOS DE RELACIÓN ENTRE REDES E INSTITUCIONES DEMOCRÁTICAS EN PERSPECTIVA EMPÍRICA}

En esta sección buscamos ilustrar las consideraciones teóricas recién hechas a partir de ejemplos extraídos de la literatura especializada. Cada ejemplo lo interpretamos desde la matriz conceptual aquí desarrollada y agregamos una ilustración complementaria para ampliar nuestra argumentación.

\section{Casos de Integración: Transición a la Democracia en Chile y el Movimiento de los Trabajadores Rurales Sin Tierra de Brasil}

La integración sinérgica de redes paraformales e instituciones democráticas tiene éxito cuando se cumplen dos condiciones: a) las instituciones democráticas son relativamente fuertes; y b) las elites tienen incentivos para acomodar redes informales que les permitan un espacio de movimiento más flexible para lograr sus objetivos. Según Peter Siavelis (2006), estas dos condiciones concurren en el caso de la transición democrática chilena, particularmente en los años 1990.

Puesto que la institucionalidad democrática chilena había sido desarrollada durante la dictadura militar (1973-1989), especialmente en la Constitución conservadora de 1980, el ajuste estricto a esa institucionalidad habría impedido un mayor acercamiento a los objetivos de democratización en el período de transición. En este contexto, sostiene Siavelis (2006), las elites democráticas desarrollaron tres mecanismos informales, cuya integración con el orden democrático habría permitido una mayor flexibilidad institucional, y con ello, un mayor ajuste a objetivos democráticos. Estos mecanismos informales son el cuoteo, la formación de un suprapartido transversal y el desarrollo de acuerdos informales extraparlamentarios. 
El cuoteo supone la distribución de cargos en la estructura pública entre los partidos de la coalición gobernante, lo que permitía dos cosas: equilibrar la alta concentración de la autoridad en la figura de la Presidencia de la República y una sensación de participación equitativa en la estructura de poder para los partidos gobernantes. En estos casos, los acuerdos no son formales (escritos), pero tienen una capacidad fáctica que permite la mantención de la alianza con alta estabilidad. Por su parte, el partido transversal tampoco es una institución formal; es más bien una red informal (paraformal) de líderes de los partidos gobernantes situados en diferentes cargos relevantes de la estructura estatal que: "saben quiénes son, estructuran relaciones informales entre ellos, entre sus partidos y la coalición, y [...] con actores sociales cuyo input es crucial para la democracia de los acuerdos" (Siavelis, 2006:45, cursivas del autor). A su vez, la democracia de los acuerdos consiste en una expansión de la comunicación de las redes del partido transversal hacia el exterior de ella, principalmente con la oposición y con actores sociales relevantes fuera del ámbito político, en particular con grandes empresarios. El objetivo de estas redes es "reducir los temores de una derecha potencialmente reaccionaria" (ibidem:48) ante las políticas del Gobierno democrático.

Varios rendimientos sinérgicos entre redes paraformales e instituciones democráticas se habrían obtenido de esto. En primer lugar, se logra la flexibilización de una institucionalidad formal fuerte pero rígida - la definida en el marco constitucional de 1980. Por medio del espacio relacional que las redes proveen, los objetivos democráticos adquieren mayor plausibilidad. Los actores son involucrados en la construcción del espacio democrático tanto por vías procedimentales (parlamento, leyes, realización de derechos fundamentales) como por vías informales (cuoteo, acuerdos extraparlamentarios, negociaciones). En segundo lugar, la integración de instituciones democráticas y redes paraformales apunta en este caso a la consolidación de un espacio social en el que los derechos fundamentales tengan plena validez, en especial luego de la experiencia dictatorial. En este sentido, se trata de la extensión del principio de inclusión plena para todas las operaciones del Estado, sin distinción de personas - en particular, sin distinción de preferencias políticas, como había acontecido durante la dictadura. En tercer lugar, desde un punto de vista normativo, la integración supone que la creación de instituciones y redes se alinea con las aspiraciones de carácter posconvencional de las instituciones democráticas. 
En este caso, el particularismo de la red informal se pone al servicio de la construcción de un horizonte democrático. La red informal apoya desde el exterior, contribuye a consolidar la estructura de derechos fundamentales. La pregunta que se abre aquí es si las prácticas que esas redes e instituciones formales introducen, en principio para apoyar el orden democrático, no llevan a distorsiones iniciales que se amplifican en el mediano y largo plazo con efectos justamente contrarios a los objetivos iniciales. En la Sección 3 desarrollamos esta discusión.

Otro ejemplo de integración sinérgica de redes paraformales e instituciones democráticas es el caso del Movimiento de los Trabajadores Rurales Sin Tierra (MST), originado en Brasil pero actualmente con alcance transnacional. El MST ha desarrollado formas de lucha con relación al derecho fundamental de la propiedad. Se constituyó en un movimiento social transnacional que ganó adeptos en diversos países por medio de vínculos de tipo relacionales, no relacionales y mediados:

relacionales (como las brigadas de militantes del MST hacia el exterior - desde Mozambique hasta Haití, pasando por Venezuela entre otros y de otros movimientos sociales hacia Brasil para conocer directamente la experiencia del movimiento); no relacionales (periódicos, revistas, páginas webs, documentos, videos); y mediados (algunas ONGs, redes y Comités de Apoyo o "Grupos de Amigos del MST", existentes principalmente en Europa y Estados Unidos, los que contribuyen a la difusión de las ideas, campañas y luchas del MST, basados en el internacionalismo y en la solidaridad política) (Bringel, 2010:207-208).

Según Bringel y Echart (2008), movimientos como el MST conviven con instancias institucionalizadas, y contribuyen tanto a una ampliación del pluralismo informativo y / o la inserción de nuevas prácticas en la agenda política, como a la creación de nuevas experiencias democráticas tanto en el mismo movimiento como en las instituciones estatales. Si bien el MST, en cuanto movimiento social, conserva una dimensión de informalidad, su carácter sinérgico en relación con las instituciones democráticas le ha permitido desarrollar o motivar la creación de un amplio dispositivo institucional con traducción formal al interior del Estado brasileño. Por ejemplo, el MST ha provocado cambios en el ámbito jurídico. Debido al MST y con la inclusión del concepto de función social de la propiedad presente en la Constitución Brasileña (Art. 5ํ, XXII - Se garantiza el derecho de propiedad; XXIII La propiedad cumplirá su función social), se produjo un cambio en el 
sentido del derecho de la propiedad en Brasil (Stamford da Silva, 2012, 2016), incluso antes del cambio en la legislación.

El carácter paraformal del MST radica en que convive con las instituciones democráticas y las moviliza hacia cambios de sus reglas y modos de operación. De este modo, el mismo movimiento adquiere una dimensión institucional y hace más robustas a las instituciones democráticas, en tanto promueve un espacio de tipo relacional (incluso transnacional), la inclusión de todos los posibles afectados por conflictos de tierra, y fomenta una orientación normativa de tipo posconvencional fundada en derechos fundamentales que mueve a las instituciones formales a una mayor concreción democrática.

\section{Casos de Superposición: Redes Delincuenciales en la Provincia de Buenos Aires y el Caso Petrobras}

En una investigación sobre el robo de autos en la Provincia de Buenos Aires, Matías Dewey $(2011,2012)$ ha podido mostrar cómo funciona empíricamente la superposición de redes de corrupción e instituciones democráticas con lógicas operativas y normativas distintas. El robo de autos constituye una red expandida que funciona en diversos niveles o dominios de red (netdoms) (White, 2008) y que conecta a las agrupaciones delincuenciales con determinados policías, funcionarios públicos y políticos que quedan incluidos selectivamente en la red. En un primer dominio de red, los policías venden protección y prestaciones a cambio de dinero a los criminales. Entre estas prestaciones están la detención-liberación de delincuentes, la eliminación de protección policial en determinadas zonas de la ciudad y la venta de información. La demanda de "protección policial" surge en vistas de la complejidad logística de las operaciones que las redes delincuenciales tienen que llevar a cabo para coordinar el robo, el desmantelamiento de autos robados, el cambio del número de serie y la venta de las partes. Por otro lado, los policías se ven estimulados a vender protección debido a los bajos salarios, especialmente, entre suboficiales, y también a las escasas posibilidades de ascenso (Dewey, 2011).

Un segundo dominio de red se desarrolla a partir del intento de la policía de eliminar las huellas del comercio ilegal. Los policías disimulan las irregularidades, manipulan las estadísticas importantes, encubren los propios actos. De esta manera, se genera la impresión de que los procedimientos formales, como también la policía misma, funcionan correctamente (Dewey, 2012:687-688). Así, el segundo dominio de red 
se asocia con el primero al encubrir las detenciones ilegales selectivas. Correspondientemente, los procedimientos legales formales (e incluso la protección policial) funcionan, como ya se dijo, en la modalidad como si, es decir, como "ficción de legalidad". Precisamente, el fingimiento de la legalidad de los actos propios hace posible, mediante el soborno (dinero) y la coacción (influencia), intervenir en el procedimiento burocrático y jurídico fijado formalmente. De esta manera, las redes informales minimizan el riesgo de rechazo de su acción y, a la vez, se superponen a las instituciones democráticas generando una relación parasitaria que incluye sus propias estrategias de ocultamiento.

Aún se puede observar un tercer dominio de red que hace todavía más robusto el fingimiento de legalidad. Se trata de relaciones selectivas entre la policía y los políticos locales y provinciales. Dewey alude aquí a un doble activismo, una relación recíproca entre prestación y contraprestación:

Por el lado de la política, hay una suerte de interferencia no oficial en la institución policial y una protección selectiva de ciertos oficiales de policía [...] Por el lado de la policía, se garantiza un control formal e informal aceptable de la criminalidad así como una provisión de ciertos "servicios" durante los períodos eleccionarios (Dewey 2011:13).

Así, "control aceptable" significa la limitación de las protestas y de la intranquilidad social por medio de la vigilancia ilegal de la criminalidad. Las ganancias que resultan de este doble activismo sirven al financiamiento de las campañas electorales, fluyen hacia la administración policial o conducen a un enriquecimiento de policías y políticos (ibidem:15-16). Con esto, la policía produce un espacio de juego libre de legalidad, en el cual las redes delincuenciales pueden operar arbitrariamente de manera superpuesta a las instituciones democráticas (incluso recibiendo "protección" de ellas).

Normativamente, la situación es aún más compleja. Toda la red se apoya en normas particularistas convencionales y en un poder que no se funda en reglas procedimentales como mecanismo de control, pero puesto que ellas se superponen con instituciones democráticas, surge la pregunta por la relación de órdenes normativos. Un punto de partida para una respuesta a esta pregunta se puede encontrar si se dirige la mirada al uso de medios simbólicos en esta situación (Parsons y Smelser, 1956; Luhmann, 2012), es decir, al dinero (soborno) y la in- 
fluencia (coacción), puestos en relación con la teoría de los regímenes de justificación de Boltanski y Thévenot (2006).

En el caso del robo de autos en la Provincia de Buenos Aires, en especial, y en las redes de corrupción, en general, los intereses personales de los partícipes están subordinados a la estructura jerárquica de la red. Así, surge un régimen normativo de justificación que está caracterizado, en primer lugar, por el particularismo de lo doméstico, donde "cada uno se posiciona entre un superior desde quien ella o él recibe un poder de acceso al valor a través del intermediario de la relación personal, e inferiores a quienes él o ella abarca o personifica" (Boltanski y Thévenot, 2006:90). Al superponerse redes de corrupción e instituciones democráticas, el ordenamiento normativo sigue formas autoritarias a las que subyace un principio jerárquico (obediencia, subordinación). Por eso es incorrecto ver normativamente la venta de protección - e igualmente cualquier forma de coacción en el mercado - como una operación de mercado. El orden del mercado supone que el interés individual es modulado teniendo en cuenta los intereses de otros (Boltanski y Thevenot, 2006:201). Este se apoya en una simpatía mínima entre los participantes (Smith, 2004), sin la cual los principios mencionados más arriba (buena fe y autonomía de las partes), no podrían funcionar. Cuando se trata de espacios en los que se superponen las redes de corrupción e instituciones democráticas, la buena fe se suplanta por la obediencia, y la autonomía de las partes, por la subordinación. La venta de protección puede funcionar como una operación de mercado. Sin embargo, vista de manera normativa, no se trata de una operación de mercado, sino de un intercambio de prestaciones basado en obediencia y la subordinación.

En tal contexto, el dinero opera como medio de influencia. En vez de recurrir a argumentos, se echa mano a la inmediatez del dinero para garantizar la obediencia y la subordinación, mientras que en el trasfondo permanece la violencia como la "presencia de lo ausente" (Luhmann, 2000b:467) en caso de que el dinero pudiese no resultar suficientemente motivador. Esto puede suceder, por ejemplo, si en el primer dominio de la red se vende información falsa y protección inefectiva; si en el segundo las huellas del delito no quedan suficientemente cubiertas, o si en el tercero los réditos no son los esperados. En tales casos, los conflictos entre las lealtades de los distintos dominios de la red escalan incrementalmente, pues "sin referencia a una perspectiva universal no hay modo de dirimir entre las exigencias de nuestras identidades" (Loewe, 
2010:447). Ante la ausencia de criterios universalistas que permitan orientar los conflictos, la violencia es empleada como medio para hacer prevalecer los objetivos, como medio venganza o de la comunicación conductual aplicada sobre los que defraudan las expectativas.

Otro ejemplo de superposición de redes de corrupción e instituciones democráticas, es el caso Petrobras en Brasil, también llamado "Operação Lava Jato". Con una fuerte repercusión en los medios de comunicación brasileños (Fernandes, 2015) e internacionales (Vacilotto, 2015), la operación se inició en marzo de 2014, cuando la Policía Federal de Curitiba investigó a redes lideradas por dueños de casas de cambio. Los datos obtenidos llevaron el Ministerio Público Federal a identificar redes de corrupción que involucraban a políticos de los partidos PP (Partido Progresista), PT (Partido de los Trabajadores), PMDB (Partido del Movimiento Democrático de Brasil) y contratistas de grandes constructoras civiles ${ }^{1}$. A ellos se les acusa de participación en un cartel de corrupción y lavado de dinero estimado en más de 10 billones de dólares. Hasta agosto de 2016 existen más de 28 investigaciones policiales abiertas a solicitud del Procurador General de la República, Rodrigo Janot sobre 47 autoridades políticas y contratistas.

Esta red de corrupción se superpone a las instituciones democráticas y, a la vez, se ocultan en ellas en tanto actúa promoviendo la optimización del financiamiento de elecciones y, paralelamente, un enriquecimiento ilícito para miembros de la red. La red funcionó por años con reglas particulares y su impacto en el funcionamiento de las instituciones democráticas consiste en un persistente debilitamiento de sus procedimientos de aspiración universalista (igualdad, trato justo y equitativo, representación legítima). Esto produce, por tanto, un espacio limitadamente relacional, de inclusión selectiva y de particularismo convencional en términos normativos (es decir, con reglas de funcionamiento desarrolladas por el propio grupo y contrarias al posconvencionalismo fundado en principios de las instituciones democráticas).

Este caso es de interés porque muestra el modo en que las instituciones democráticas pueden reaccionar frente a la acción parasitaria y oculta de las redes de corrupción. El uso del instituto jurídico de la "delación compensada" (delação premiada en portugués) permitió obtener datos e informaciones del esquema de corrupción. Si bien la figura surge en el año 2000 en una medida provisoria que modificaba la Lei Antitruste, la 
Lei Anticorrupção de 2013 ha hecho más frecuente su aplicación en el derecho brasileño en la investigación de casos que involucran empresas como Petrobras en la "Operação Lava Jato". Esta aplicación más recurrente ha motivado discusiones acerca de la constitucionalidad del mecanismo: jurídicamente atentaría contra el derecho fundamental de no autoincriminación y éticamente no otorga garantías de veracidad en el relato del delator que conduciría a identificar a los demás participantes del ilícito (Sales y Bannwart, 2015). No obstante, el giro hacia una justicia colaborativa en justicia criminal, el carácter no obligatorio de la delación y su orientación al interés público, han legitimado el uso del instituto, cuya información debe ser de todos modos confirmada en juicio (Gomes y Rodrigues da Silva, 2015). Esto muestra cómo las instituciones formales recurren a flexibilizaciones operativas internas para desprenderse del parasitismo al que las someten las redes de corrupción. Es decir, así como en el caso de redes paraformales, las redes de corrupción desafían las reglas y modos de operación formal, en este caso, sin embargo, el objetivo es extraer a la red de su ocultamiento y someterla al principio posconvencional de la igualdad ante la ley.

\section{Casos de Desacoplamiento: Favelas y Zonas Periféricas Urbanas en Brasil}

Favela y periferia son dos formas de designar las desigualdades territoriales urbanas en el caso de Brasil (Gomes Ribeiro, 2015), como también formas de construir discursivamente un espacio de segregación generalizada que oscurece la diversidad social (Valladares, 2005) y justifica estrategias violentas de intervención en nombre de la seguridad pública (Machado da Silva, 2010). Pero no se trata solo de discurso, sino también de prácticas que lo escenifican y que hacen evidente la tensión, que en esos territorios tiene lugar, entre el orden propio y aquel que promueven las instituciones democráticas y los derechos fundamentales. En palabras de Deffner:

como consecuencia de la ausencia de poder institucional y el desplome de la policía y el orden público, el control de las favelas y la autoridad de interpretación sobre temas de seguridad y protección compete al "poder paralelo" que, sobre todo, en las grandes favelas del país [Brasil] tiene la forma de grupos paramilitares y comandos (2007:215).

"Poder paralelo" significa un poder que no se funda en reglas de instituciones democráticas, y que tampoco puede ser entendido como desobediencia civil o derecho de resistencia (Buzanello, 2014). Cuando el 
acoplamiento de la política y el derecho se desestabiliza, surgen vacíos en la universalización de los derechos fundamentales. Si a esto se agrega la formación de un discurso histórico de exclusión y estigmatización social que homogeniza la situación de los habitantes de las favelas y de otras zonas urbanas periféricas y que oculta la pluralidad de su realidad social (Valladares, 2000, 2005), entonces ese mismo discurso opera continuamente en favor de prácticas de violencia y de excepción de derechos en el espacio de las favelas, sea como intervención estatal o como acción de redes criminales, como lo ha mostrado Feltran (2008).

Concretamente, esto significa que las instituciones democráticas sufren un relativo desplazamiento del espacio social en cuestión. Si este es el caso, los afectados tienen que buscar posibilidades alternativas de organización social. Se requiere de equivalentes funcionales para las prestaciones de las instituciones formales que han sido desplazadas (prestaciones como el monopolio legítimo de la violencia física, servicios básicos, protección y seguridad ante el uso de la violencia), o también de determinados mecanismos que actúen como zonas de frontera entre dinámicas sociales consideradas legítimas y el "mundo del crimen" - "mundo del crimen" que surge como efecto de distintas crisis interrelacionadas de los habitantes de zonas periféricas (de trabajo, de ascenso social, de transformaciones religiosas) y que se va paulatinamente asociando con el "crecimiento de la violencia criminal en esos territorios" (Feltran, 2008:97).

En estas situaciones, grupos criminales y comandos asumen en buena parte el monopolio del uso de la violencia. Desde luego, no según los criterios de los derechos fundamentales, sino según normas particularistas que están directamente asociadas con la conservación del contexto de acción y sus límites. En la mayoría de los casos, se trata de carteles de narcotráfico que luchan por el control de los puntos de venta de drogas dentro de las favelas y que reclutan miembros directa e indirectamente para la red (Huguet y de Carvalho, 2008). Los miembros directos son inmediatamente incluidos en actividades ilegales. Los miembros indirectos se pueden diferenciar en dos tipos: por un lado, se trata de habitantes que, por temor a represalias, no tienen otra opción que proteger a los delincuentes; por otro lado, se trata de personas que se hacen dependientes de los servicios de las redes. En estos casos, la inclusión adquiere un carácter coactivo: es dependiente de la amenaza ilegítima de uso de la fuerza. 
Los miembros directos tienen que ocuparse de la diferenciación del propio grupo de red frente a otros grupos y de defender los límites externos contra las intervenciones policiales. La policía, al mismo tiempo, no simboliza siempre la presencia del Estado de derecho. Por un lado, los carteles de droga intervienen en las estructuras policiales para dejar que las operaciones económicas ilegales continúen su curso, con lo que la policía "complementa" su sueldo por la vía informal de la corrupción - como en el caso del robo de autos en la Provincia de Buenos Aires. Por otro lado, según lo ha documentado Feltran (2012:247), la misma policía puede actuar fuera del Estado de derecho, como aconteció en los crímenes de mayo de 2006 en São Paulo con alrededor de 493 homicidios, de los cuales, según entidades civiles, aproximadamente la mitad habían sido practicados por policías. Debido a la criminalidad y el ejercicio de la violencia, la presencia simbólica de las instituciones democráticas en los espacios controlados por redes criminales se reduce. Y no solo se reduce, sino que el propio espacio social queda definido en el discurso en términos de estigmatización:

El evento crítico [mayo de 2006] dejaba claro que las posibilidades de subjetivación de esta generación nacida en las favelas, ya está sometida a la figuración pública de violencia urbana. Los muertos de la contraofensiva policial eran leídos como incremento del orden urbano (Feltran, 2012:248).

Justamente ello contribuye a la reproducción y pseudojustificación de excesos policiales que

sobrepasan sistemáticamente su función constitucional de uso limitado de la fuerza, [pues] ellos son fruto de una perspectiva colectivamente construida sobre lo que sería deseable en términos de mantención del orden público (la gramática de la violencia urbana) (Machado da Silva, 2010:293).

Como resultado de ello, se tienen que buscar equivalentes para las prestaciones de las instituciones formales o formas de establecer nexos con el exterior. Las organizaciones criminales proveen servicios. Ofrecen, por ejemplo, abastecimiento de agua o financiamiento para entierros, promueven el mercado para mercancías robadas e incluso transportan a los habitantes a centros comerciales y hospitales fuera de las favelas (Arias y Rodrígues, 2006). A la vez, crece la dependencia de los miembros indirectos de estas redes respecto de los nodos centrales de la red-crece, por tanto, la inclusión coactiva. El espacio controlado por 
la redes de traficantes se transforma en un espacio "contenedor", en el cual las condiciones para la implementación de los derechos fundamentales son al menos débiles.

Buena parte de la dualidad discursiva favela/ciudad, que estigmatiza a este espacio social y lo priva de la observación de su diversidad (Valladares, 2005) y de los vínculos que se establecen con el exterior, deriva precisamente de esta debilidad en la implementación de derechos fundamentales. Por el contrario, en varios de estos espacios se despliegan protodominios de red que se ocupan directamente de un amplio rango de satisfacción de necesidades: uso comunitario del espacio, intercambio de bienes escasos, viviendas y agua compartida, jardines y propiedades comunes, protección de los parientes y los conocidos (Dawsey, 1989). En estos protodominios los habitantes se mueven constantemente, crean conexiones y sociabilidad. Estas relaciones de reciprocidad funcionan incluso como redes paraformales, sinérgicas con las instituciones democráticas y con las redes de intermediación de organismos no gubernamentales. Se crean espacios comunes donde uno se puede encontrar, donde se intercambian bienes y se asumen medidas para la protección y la seguridad colectivas, se intentan esquivar los riesgos de la marginalidad y producir conexiones con el mundo externo, sobre todo, con organizaciones no gubernamentales (Arias, 2004).

De esta manera, se vuelven a ganar algunos "derechos", aunque estos refieren al colectivo y no a personas individuales en un sentido moderno. No obstante, son precisamente estas conexiones las que hacen atractiva la comunidad para las redes criminales: las observan como un espacio de potencial protección. Cuando estas redes criminales se internan en estos dominios de reciprocidad, surgen inmediatamente formas de dependencia y jerarquización, que, en efecto, funcionan sobre la base de la violencia y el control, pero también se fundan en una estructura de sentido normativa, de todos modos particularista. La situación es, entonces, paradójica: en la estructura de reciprocidad de la favela uno se convierte en parte del colectivo; desde el entorno interno, esto es, desde la red criminal, se es observado como cuerpo. Nunca se trata de personas con derechos fundamentales de inclusión plena.

En esta situación precaria, los habitantes afectados intentan extender la estructura de reciprocidad a la red criminal. Dado que no se puede 
confiar plenamente en la policía, en la favela se desarrolla una ficción normativa que sirve al cumplimiento de expectativas de seguridad:

una estrategia relevante empleada [por los habitantes de las favelas] es la inversión del orden social: se censura la violencia policíaca y se sugiere que los traficantes con quienes ellos tienen que vivir, los proveen de un alto grado de seguridad en su comunidad, mayor el que existe en las áreas circundantes. De este modo, la favela, vista como peligrosa y marginal por la sociedad como un todo, es vista por sus residentes como un lugar de refugio y seguridad (Arias y Rodrigues, 2006:60).

La norma indica que los habitantes afectados, como contraprestación por la seguridad interna, deben ofrecer, por ejemplo, discreción en la esfera pública acerca del empleo de la violencia al interior de la favela, respeto por los narcotraficantes, información sobre las actividades policiales y protección frente a los policías. En oportunidades los narcotraficantes tienen que actuar como "jueces" para decidir conflictos entre habitantes (Arias y Rodrigues, 2006:68), incluso sobre la base de preceptos de carácter religioso (Arias, 2014). Sin embargo, el problema normativo fundamental consiste en que se intenta poner en relación normas de reciprocidad con principios jerárquicos (obediencia y subordinación). Surge, entonces, la ficción de una reciprocidad con las redes criminales. En estos casos, las expectativas recíprocas generan un vínculo de lealtades particularistas altamente contextualizado y ajeno al orden social universalista que promueven los derechos fundamentales (Loewe, 2010).

Esto es también lo que sucede en el caso de los "tribunales del crimen" (Feltran, 2010), en los cuales "hermanos" (miembros bautizados) del Primeiro Comando da Capital (PCC, principal facción criminal de São Paulo) organizan "debates" para dirimir disputas y ejecutar sentencias en causas pequeñas, en otras de mediana intensidad y en casos de vida o muerte. En los debates se plantean argumentos de ambas partes y las sentencias pueden ir desde advertencias (para causas pequeñas), suspensiones o exclusiones del tráfico local (para casos medianos), hasta la muerte de algún individuo, lo que exige el consenso entre varios "hermanos". Según Feltran (2010), esta autorregulación ha sido el principal factor de la disminución del crimen en São Paulo. Ello establece una disputa de legitimidad entre la justicia particular del PCC y la justicia estatal, la que a pesar de ser reconocida con contenidos universalistas por los habitantes de la periferia, fracasa en sus procedimientos de aplicación: "el funcionamiento del poder judicial es lento, 
discrimina por posición social, lugar de habitación, color de piel e idiosincrasias de clase, además de estar sometido a la experticia técnica de los abogados" (ibidem:71). Solo la "justicia del crimen" (justicia particularista) sería la que se aplica de igual manera para todos (esto es, de modo universalista).

Sea como fuere, el desacoplamiento entre este espacio social y las modalidades de las instituciones democráticas, en este caso de tipo normativo, sigue teniendo lugar. Se producen dos "justicias", aun cuando esto surja de una decisión instrumental de los habitantes de periferias derivada de su experiencia cotidiana (Feltran, 2010).

\section{DISCUSIÓN E IMPLICACIONES DEL MODELO PROPUESTO}

Hemos analizado hasta aquí la relación entre distintos tipos de redes informales e instituciones democráticas. En el primer tipo de relación, el vínculo es sinérgico; en los otros dos, las redes informales operan en un sentido conflictivo con las instituciones democráticas.

Una primera línea de discusión consiste en la argumentación alternativa a los problemas de concretización de derechos fundamentales y, en general, de eficacia práctica del derecho en América Latina que este artículo ofrece. Buena parte de las explicaciones existentes de este problema se agrupan en tres tipos de argumentos interrelacionados con: a) la debilidad de las instituciones jurídicas en América Latina (Garzón Valdés, 1997; Schor, 2006; Olvera, 2010; García 2011, 2014); b) la debilidad de la sociedad civil (Brysk, 2000; Kruijt, 2001; Oxhorn, 2011); y c) un sustrato cultural reactivo a la individualidad y racionalidad de la modernidad (Morandé, 1987; Véliz, 1995; Mignolo, 2005). En la versión más sofisticada de las teorías de la modernización, estos argumentos podían correlacionarse con el hecho de que una cultura de tipo tradicionalista no produciría personalidades críticas que desarrollaran instituciones fuertes (Germani, 1981). Del mismo modo, en la idea de matriz sociopolítica de Garretón (1983), la escasa autonomía de la sociedad civil genera una adhesión frágil al régimen político y la construcción del Estado democrático.

En términos generales, estos argumentos pueden ser aún correctos cuando se observa el problema de la concretización de derechos como un problema endógeno a las propias instituciones. Sin embargo, al hacerlo así se evita pensar en si, paralelamente, se han construido formas de organización social alternativas que tengan un factor de moti- 
vación suficientemente alto para competir con la organización moderna basada en derechos fundamentales. Las redes paraformales no compiten, sino que complementan a las instituciones democráticas. Sin embargo, cuando redes de corrupción y criminalidad se articulan de manera tal que permiten un acceso no procedimental (con inclusión y exclusión selectiva) a las prestaciones de las instituciones democráticas, o cuando asumen el control de territorios por medio de coerción y violencia (inclusión y exclusión coactiva), entonces la suspensión o desplazamiento de los derechos fundamentales ya no es entendida como un problema endógeno. Ya no se puede superar solo fortaleciendo las instituciones democráticas o promoviendo la autonomía de los actores sociales para que de ese modo se transformen las condiciones de base.

Las redes de corrupción y criminalidad muestran un nivel de operación e institucionalización alto. Lo que en esos casos acontece es que los propios límites entre lo formal y lo informal, lo lícito y lo ilícito, comienzan a hacerse difusos para los participantes (Silva Telles, 2007, 2009), por una parte, pues esas mismas redes emplean y, a la vez, ocultan su acción tras una fachada procedimental, y por otro, porque los discursos justificadores en espacios criminales o de corrupción legitiman el mundo propio ante un orden democrático que se percibe injusto, discriminatorio y desigual (Feltran, 2010; Machado da Silva, 2010; Silva Telles, 2010). Esta sensación se incrementa cuando Estados democráticos de derecho intervienen en estos espacios por medio de estrategias que, en sí mismas, suponen una suspensión de derechos fundamentales, como las intervenciones armadas en zonas periféricas (Feltran, 2008), el combate de carteles de droga en México (Morales, 2011) o Colombia (Medina, 2012), o la persecución de grupos terroristas mediante la suspensión de garantías en lo que se denomina un derecho penal del enemigo, de tercera velocidad o derecho penal de la seguridad (Carnevali, 2010).

Una segunda línea de discusión de este artículo deriva de las formas de relación entre redes informales e instituciones democráticas. Ciertamente, el análisis de redes informales no es nuevo en el contexto latinoamericano, pero la persistencia del tema, sin embargo, obliga a constantes revisiones y actualizaciones (Lomnitz, 1977; Wiarda y Klein, 1996; Stokes, 2001; Helmke y Levitsky, 2006). Una clasificación alternativa de interés para estos efectos es la desarrollada por Helmke y Levitsky (2006). Ella distingue instituciones informales complementarias (que no transgreden los procedimientos formales pero tampoco 
producen efectos sustantivos), de acomodación (alteran las normas procedimentales sin transgredirlas), competitivas (son contrarias a las normas procedimentales y las vulneran abiertamente), y sustitutivas (buscan compatibilidad con normas procedimentales pero las reemplazan ante la debilidad de ellas) (ibidem:13-19).

Los autores, sin embargo, se centran en el concepto de institución propio de la ciencia política, por lo que la aproximación no establece una diferencia entre la concepción de espacio, las formas de coordinación social y las referencias normativas involucradas, que son más bien distinciones sociológicas que aportan un sentido más amplio a la interpretación, particularmente a partir de las relaciones que se pueden establecer entre esas tres dimensiones revisadas en la propuesta realizada en este artículo. Por otro lado, al centrarse en el concepto de institución, la clasificación de Helmke y Levitsky no apunta directamente a la dinámica de redes y a las transformaciones que pueden sufrir estas relaciones en el tiempo. Por ejemplo, la integración de redes paraformales e instituciones democráticas en el caso de la transición chilena (acomodación en el caso de Helmke y Levitsky) ciertamente facilitó el proceso, actuó efectivamente como una forma de acomodación de una institucionalidad rígida (la Constitución de 1980) a objetivos de mayor democratización. Sin embargo, como Siavelis indica, las redes extendidas hacia actores empresariales fuera del ámbito político buscaban asegurar que los "intereses comerciales habían sido tomados en cuenta al elaborar presupuestos y legislaciones económicas controvertidas" (Siavelis, 2006:50).

Esto origina una situación de desigualdad de trato con los actores favorecidos que genera privilegios contrarios al tipo de orden social que los derechos fundamentales promueven. Del mismo modo, la institución informal de la democracia de los acuerdos (en sí misma de naturaleza antidemocrática por su carácter extraparlamentario e informal) produce "un problema de largo plazo en la consolidación de la democracia" (ibidem:51). Así, en la dinámica de integración de redes paraformales e instituciones democráticas también podría existir una dimensión competitiva y una sustitutiva: en vista de un objetivo que se juzga en el momento de mayor relevancia, se pueden emplear mecanismos no procedimentales para sostener una arquitectura institucional que carece de flexibilidad formal (sustitución). Cuando se considera la relación en términos temporales, un tipo de relación puede transformarse, de manera no intencional, en otra. 
En fin, una tercera línea de discusión se asocia a la dimensión normativa de las relaciones entre redes e instituciones democráticas. En los casos de desacoplamiento de redes de criminalidad e instituciones democráticas, nos parece que la situación excede normativamente las formas de competencia descritas por Helmke y Levitsky (2006). Esto se aprecia de modo especial en el tipo de inclusión/exclusión coercitiva que se aplica en estos espacios a través de la amenaza de uso de una violencia física no mediada por el Estado de derecho, como especialmente lo ha mostrado Feltran $(2008,2010,2012)$ en el caso de las zonas periféricas en São Paulo. Las redes de criminalidad no solo vulneran garantías constitucionales, sino que las sustituyen en determinados espacios sociales. Bajo la condición de amenaza por parte de traficantes, la violencia remite a la mera sobrevivencia para los habitantes de las zonas militarizadas: "Cualquiera puede atacar, cualquiera puede defenderse, cualquier individuo tiene que ser coaccionado si se da el caso" (Luhmann, 2005a:271).

En estos casos, la forma de construcción de expectativas normativas es distinta: no se confía primariamente en instituciones, sino en las propias habilidades de sobrevivencia y en la experiencia cotidiana en esos espacios. Se tiene que reaccionar rápida e inequívocamente a estímulos (advertencias, órdenes, instrucciones, acciones o movimientos corporales sospechosos). Cuanto más rápida e inequívoca sea la reacción, mayores son las oportunidades de no ser violentamente coaccionado. Por el contrario, las dilaciones pueden ser interpretadas como enemistad o resistencia por parte de quienes detentan el uso de las armas, pues en general cualquier demora puede ser decisiva para la propia sobrevivencia. Asimismo, si los habitantes de estas zonas reaccionan positivamente a la expectativa de protección de los delincuentes, tampoco se puede derivar de ahí ninguna promesa de que futuros errores puedan ser tolerados. La norma no se institucionaliza. Apoyar una vez a delincuentes, criminales o narcotraficantes no suma confianza en ninguna cuenta desde la que se pueda extraer libertad de decisión futura (Gambetta, 2008). Se tiene que estar siempre del lado correcto y, para eso, hay que reaccionar rápido y, sobre todo, adecuadamente.

\section{CONCLUSIÓN}

En este artículo hemos propuesto un modelo conceptual de orientación sociológica para analizar las formas de relación entre redes informales e instituciones democráticas. Las hemos descrito teóricamente e ilustrado con ejemplos de la literatura sobre América Latina. Estas for- 
mas de relación son: una integración de redes e instituciones democráticas, una superposición de ellas y, finalmente, un desacoplamiento de ambas.

Una primera contribución de esta propuesta es que con ella es posible ir un paso más allá de aproximaciones más bien dualistas al fenómeno de las redes, tales como redes de simpatía u oposición (Holzer, 2006), solidarias o subversivas (Ledeneva, 2013), de reciprocidad o compadrazgo (Lomnitz, 1977); asociativas o clientelares (Corrochano, 2002), de dominación política o de protección (Auyero, 2012), basadas en principios jurídicos o basadas en principios dinásticos (Bourdieu, 2005). Aunque estas distinciones no sean equivocadas, sugieren situaciones duales que las dinámicas de vinculación de redes e instituciones democráticas muchas veces exceden, sea por la hibridación entre modalidades distintas (por ejemplo, en los modos de institucionalización democrática del MST y su mantención como movimiento paraformal), por sus efectos antagónicos en el tiempo (como las redes de la transición política en Chile, que en un primer momento favorecen la democracia pero en el largo plazo la debilitan), por la superposición de niveles en el espacio social en que la relación se produce (como en el caso del robo de autos en la provincia de Buenos Aires, que vincula redes de delincuentes, redes de policía y delincuentes, redes de policía con organismos burocráticos y redes de políticos con policía), o por las luchas de desacoplamiento entre redes e instituciones democráticas que pueden tener lugar (como en el caso de zonas periféricas urbanas a propósito del ejemplo de Brasil).

Una segunda contribución de nuestra propuesta reside en la vinculación del fenómeno de redes con el tipo de orden social que promueven los derechos fundamentales. Se puede afirmar que la integración entre redes paraformales e instituciones democráticas se orienta al fomento y consolidación reflexiva de ese orden, como el caso del MST lo muestra. Sin embargo, en algunos casos, los privilegios derivados de una integración original de redes e instituciones democráticas pueden derivar en desigualdades ponen en tensión la institucionalidad, como el caso de la transición política chilena lo ilustra. Por su parte, la relación de superposición utiliza estratégicamente el tipo de orden social que promueven los derechos fundamentales para los fines de las redes de corrupción y en ese sentido lo interviene, lo degrada y lo aprovecha parasitariamente. Bajo una forma de inclusión y exclusión selectiva, determina quiénes son favorecidos por los rendimientos de la red y, al 
hacerlo, produce una situación de desigualdad generalizada en la concretización de los derechos fundamentales. Finalmente, la relación de desacoplamiento tiende a desplazar el tipo de orden social promovido por los derechos fundamentales y lo sustituye por equivalentes basados en mecanismos de inclusión y exclusión coercitiva. Estos operan por medio de la amenaza explícita del uso de la violencia física no legítima y son justificados por una normatividad de carácter particularista preconvencional contraria al posconvencionalismo de los derechos fundamentales.

El modelo propuesto también contribuye, en tercer lugar, al desarrollo de una aproximación sociológica de la relación entre redes e instituciones democráticas. Si bien el modelo de Helmke y Levitsky entrega una observación de alto interés desde el punto de vista institucional de la ciencia política, la aproximación desplegada en este artículo extiende el foco de análisis a la dimensión espacial, a las formas de coordinación social y a los componentes normativos que se ponen en juego en la relación entre redes e instituciones democráticas. Paralelamente, el modelo propuesto vincula entre sí estos componentes para cada uno de los tipos de relación identificada, con lo que ofrece una mirada sociológica integral de esas relaciones. Por medio de esa mirada integral, es posible interpretar bajo un mismo esquema analítico (de dimensiones equivalentes) situaciones disímiles, las que, sin embargo, se hacen comparables gracias a la propuesta conceptual. Ello hace posible ofrecer un marco de interpretación suficientemente general para captar diversas situaciones sociales (diversas formas de relación entre redes e instituciones democráticas) e incluirlas en una misma lógica de análisis sociológico, pero también suficientemente específico para lograr diferenciar esas situaciones en cuanto a sus formas de vinculación con el espacio, sus modalidades de coordinación social y sus tipos de normatividad.

Una última contribución del modelo conceptual consiste en sugerir una explicación alternativa al problema de la concretización de derechos en América Latina, tradicionalmente observado como un problema de debilidad endógena de las propias instituciones latinoamericanas. $\mathrm{Si}$ bien las argumentaciones sobre la debilidad de las instituciones jurídicas, la debilidad de la sociedad civil, o la debilidad de los derechos fundamentales como efecto de un sustrato cultural opuesto a la racionalidad moderna han sido comunes para dar cuenta de los problemas de la modernidad latinoamericana, es necesario considerar también la 
fuerza de motivación de otras formas de organización social alternativas al orden promovido por los derechos fundamentales. Cuando se gira la mirada a la alta capacidad de organización que alcanzan las redes informales y a las relaciones que pueden establecer con el orden social promovido por los derechos fundamentales, entonces las explicaciones endógenas se pueden complementar con razones externas: no se trata solo del carácter incompleto de las propias instituciones, sino de la emergencia de formas de organización social alternativas. Con ello se puede tener un panorama más acabado de las características de la modernidad latinoamericana y de sus limitaciones.

(Recebido para publicação em outubro de 2015)

(Reapresentado em março de 2016)

(Aprovado para publicação em abril de 2016)

\section{NOTA}

1. Para detalles ver http://lavajato.mpf.mp.br/lavajato/index.html. 


\section{REFERENCIAS}

ALEXY, Robert. (1983), Theorie der juristichen Argumentation. Frankfurt, Suhrkamp.

. (2006), Discourse Theory and Fundamental Rights, en A. Menéndez y E. Eriksen (eds.), Arguing Fundamental Rights. Springer, Dordrecht, pp. 15-32.

ARIAS, Enrique. (2004), “Faith in Our Neighbors: Networks and Social Order in Three Brazilian Favelas". Latin American Politics and Society, vol. 46, no 1, pp. 1-38.

. . (2014), “Violence, Citizenship, and Religion in a Rio de Janeiro Favela”. Latin American Research Review, no 49, pp. 149-167.

; RODRIGUES, Corinne. (2006), “The Myth of Personal Security: Criminal Gangs, Dispute Resolution, and Identity in Rio de Janeiro's Favelas". Latin American Politics E Society, vol. 48, no 4, pp. 53-81.

AUYERO, Javier. (1999), “'From the Client's Point(s) of View': How Poor People Perceive and Evaluate Political Clientelism". Theory \& Society, no 28, pp. 297-334.

. (2012), "Poor People's Lives and Politics: The Things a Political Ethnographer Knows (and doesn't Know) After 15 Years of Fieldwork". New Perspectives on Turkey, no 46, pp. 95-127.

BOLTANSKI, Luc; THÉVENOT, Laurent. (2006), On Justification. Princeton, Princeton University Press.

BOURDIEU, Pierre. (2005), “De la Casa del Rey a la Razón de Estado. Un Modelo de la Génesis del Campo Burocrático", en L. Wacquant (coord.), El Misterio del Ministerio. Pierre Bourdieu y la Política Democrática. Barcelona, Gedisa, pp. 43-70.

BRINGEL, Breno. (2010), "Ativismo Transnacional, o Estudo dos Movimentos Sociais e as Novas Geografias Pós-coloniais". Estudos de Sociologia: Revista do Programa de Pós-Graduação em Sociologia da UFPE, vol. 16, no 2, pp.185-216.

. (2012), “Com, Contra e para Além de Charles Tilly: Mudanças Teóricas no Estudo das Ações Coletivas e dos Movimentos Sociais”. Sociologia \& Antropologia, vol. 2, no3, pp. 43-67.

; DOMINGUES, José Maurício. (2015), Global Modernity and Social Contestation. London, Sage.

BRINGEL, Breno; ECHART, Enara. (2008), “Movimentos Sociais e Democracia: Os Dois Lados das 'Fronteiras'”. Caderno CRH, vol. 21, no 54, pp. 457-475.

BRYSK, Alison. (2000), "Democratizing Civil Society in Latin America”. Journal of Democracy, vol. 11, no 3, pp. 151-166.

BUZANELLO, José Carlos. (2014), Direito de Resistência Constitucional. Rio de Janeiro, Freitas Bastos.

CARNEVALI, Raúl. (2010), “El Derecho Penal frente al Terrorismo. Hacia un Modelo Punitivo Particular y sobre el Tratamiento de la Tortura". Revista de Derecho, vol. 35, no2, pp. 109-145.

. (2014), “Hacia un Injusto Penal. De la Criminalidad Organizada. Una Propuesta a modo de Lege Ferenda". Revista de Derecho, vol. 21, no 2, pp. 61-101. 
CORROCHANO, David. (2002), "El Clientelismo Posmoderno". Perfiles Latinoamericanos, no 20, pp. 131-156.

DAWSEY, John. (1989), “Organização do Espaço em Favelas: Disciplina e Reciprocidade". Impulso, vol. 3, no 6, pp. 7-16.

DEFFNER, Veronika. (2007), “Soziale Verwundbarkeit im 'Risikoraum Favela': Eine Analyse des sozialen Raumes auf der Grundlage von Bourdieus 'Theorie der Praxis'", en R. Wehrhahn (ed.), Risiko und Vulnerabilität in Lateinamerika. Kiel, Kieler Geographische Schriften 117, pp. 207-232.

. (2011), “Second Class Citizens". D+C, vol. 38, no 3, pp. 110-112.

DEWEY, Matías. (2011), “Fragile States, Robust Structures: Illegal Police Protection in Buenos Aires", GIGA Working Papers. Disponible en: http://www.giga-hamburg. de/de/system/files/publications/wp169ãdewey.pdf.

. (2012), "Illegal Police Protection and the Market for Stolen Vehicles in Buenos Aires". Journal of Latin American Studies, vol. 44, no 4, pp. 679-702.

DOMINGUES, José Maurício. (2008), Latin America and Contemporary Modernity: A Sociological Interpretation. London, Routledge.

FELTRAN, Gabriel de Santis. (2008), “O Legítimo em Disputa: As Fronteiras do 'Mundo do Crime' nas Periferias de São Paulo". Dilemas. Revista de Estudos de Conflito e Controle Social. Rio de Janeiro, vol. 1, no 1, pp. 93-123.

. (2010), “Crime e Castigo na Cidade: Os Repertórios da Justiça e a Questão do Homicídio nas Periferias de São Paulo". Caderno CRH, vol. 23, no 58, pp. 59-73.

. (2012), “Governo que Produz Crime, Crime que Produz Governo: O Dispositivo de Gestão do Homicídio em São Paulo (1992-2011)”. Revista Brasileira de Segurança Pública, vol. 6, no 2, pp. 232-255.

FERNANDES, Carla Montouri. (2015), “Da Mídia Impressa à Audiovisual: O Agendamento Intermidiático do Escândalo da Petrobras no Jornal Nacional". Líbero, vol. 18, no 35, pp. 111-122.

GAMBETTA, Diego. (2008), Trust. Making and Breaking Cooperative Relations. Oxford, Basil Blackwell.

GARCÍA, Mauricio. (2011), “La Ineficacia del Derecho y la Cultura del Incumplimiento de Reglas en América Latina", en C. R. Garavito (coord.), El Derecho en América Latina. Buenos Aires, Siglo XXI Editores, pp. 161-184.

. (2014), La Eficacia Simbólica del Derecho. Bogotá, Instituto de Estudios Políticos y Relaciones Internacionales Universidad Nacional de Colombia.

GARRETÓN, Manuel. (1983), El Proceso Político Chileno. Santiago, Flacso.

GARZÓN VALDÉS, Ernesto. (1997), "Funktionen des Rechts in Lateinamerika". Ibero-Amerikanisches Archiv, vol. 23, n으 3-4, pp. 321-363.

GERMANI, Gino. (1981), The Sociology of Modernization. New Brunswick, London, Transaction Books.

GOMES, Luiz Flávio; RODRIGUES DA SILVA, Marcelo. (2015), “Criminalidade Organizada e Justiça Penal Negociada: Delação Premiada”. FIDES, vol. 6, no 1, pp. 164-175. 
GOMES RIBEIRO, Marcelo. (2015), “Território e Desigualdades de Renda em Regiões Metropolitanas do Brasil". DADOS - Revista de Ciências Sociais, vol. 58, no 4, pp. 913-949.

GOHN, Maria da Gloria; BRINGEL, Breno. (2013), Movimentos Sociais na Era Global. Petrópolis, Vozes.

GROPPA, Octavio; HOEVEL, Carlos. (2014), Economía del Don. Perspectivas para Latinoamérica. Buenos Aires, Ciudad Nueva.

HABERMAS, Jürgen. (1998), Faktizität und Geltung. Frankfurt, Suhrkamp.

HELMKE, Gretchen; LEVITSKY, Steven (eds.). (2006), Informal Institutions and Democracy. Baltimore, The Johns Hopkins University Press.

HOLZER, Boris. (2006), Netzwerke. Bielefeld, Verlag.

HUGUET, Clarissa; DE CARVALHO, Ilona. (2008), “Violence in the Brazilian Favelas and the Role of the Police". New Directions in Youth Development, no 119, pp. 93-109.

KELSEN, Hans. (2005), Teoría general del Estado. México, Coyoacán.

KJAER, Poul. (2014), Constitutionalism in the Global Realm. Oxon, Routledge.

KNORR-CETINA, Karin. (1981), The Manufacture of Knowledge. Oxford, Pergamon Press.

KRUIJT, Dirk. (2001), “Low Intensity Democracies: Latin America in the Post-dictatorial Era". Bulletin of Latin American Research, vol. 20, no 4, pp. 409-430.

LATOUR, Bruno; WOOLGAR, Steve. (1986), Laboratory Life. The Construction of Scientific Facts. Princeton, Princeton University Press.

LECHNER, Norbert. (2001), “Modernización, Malestar y Gobernabilidad”, en J. Labastida; A. Camou (coords.), Globalización, Identidad y Democracia. México, Siglo XXI.

LEDENEVA, Alena. (2013), Can Russia Modernise? System, Power Networks and Informal Governance. Cambridge, Cambridge University Press.

LOEWE, Daniel. (2010), “Liberalismo, Inmigración y Justicia Global: Obligaciones Especiales Hacia Nuestros Conciudadanos". Isegoría, no 43, pp. 435-458.

LOMNITZ, Larissa. (1977), Networks and Marginality. New York, Academic Press. . (1993), Cómo Sobreviven los Marginados. México, Siglo XXI.

LUHMANN, Niklas. (1996), Protest. Frankfurt, Suhrkamp.

(1999), Grundrechte als Institution. Ein Beitrag zur politischen Soziologie. Berlin, Druncker \& Humblot.

_. (2000a), Organisation und Entscheidung. Wiesbaden, VS Verlag.

_. (2000b), Die Politik der Gesellschaft. Frankfurt, Suhrkamp.

_. (2002), El Derecho de la Sociedad. México, D.F., Universidad Iberoamericana.

. (2005a), "Inklusion und Exklusion", en N. Luhmann, Soziologische Aufklärung 6.

Wiesbaden, VS Verlag, pp. 226-251.

. (2005b), "Symbiotische Mechanismen", en N. Luhmann, Soziologische Aufklärung

3. Wiesbaden, VS Verlag, pp. 262-280.

. (2012), Theory of Society. Stanford, Stanford University Press. 
MACHADO DA SILVA, Luiz Antônio. (2010), “`Violência Urbana', Segurança Pública e Favelas: O Caso do Rio de Janeiro Atual”. Caderno CRH, vol. 23, no 59, pp. 283-300.

MASCAREÑO, Aldo. (2010), Diferenciación y Contingencia en América Latina. Santiago, Ed. Universidad Alberto Hurtado.

. (2012), Die Moderne Lateinamerikas. Bielefeld, transcript Verlag.

; ARAUJO, Kathya. (2012), Legitimization in World Society. Farnham/Burlington, Ashgate.

MEDINA, Carlos. (2012), “Mafia y Narcotráfico en Colombia. Elementos para un Estudio Comparado", en A. Vargas (coord.), El Prisma de las Seguridades en América Latina. Escenarios Regionales y Locales. Buenos Aires, Clacso, pp. 139-170.

MIGNOLO, Walter. (2005), La Idea de América Latina. Barcelona, Gedisa.

MORALES, Carlos. (2011), “El Fracaso de una Estrategia: Una Crítica a la Guerra Contra el Narcotráfico en México, sus Justificaciones y sus Efectos". Nueva Sociedad, no 231, pp. 4-13.

MORANDÉ, Pedro. (1987), Cultura y Modernización en América Latina. Madrid, Encuentro.

NEVES, Marcelo. (2007), A Constitucionalização Simbólica. São Paulo, Acadêmica. . (2013), Transconstitutionalism. Oxford, Hart Publishing.

OLVERA, Alberto (coord.). (2010), La Democratización Frustrada. Limitaciones Institucionales y Colonización Política de las Instituciones Garantes de Derechos y de Participación Ciudadana en México. México, Centro de Investigaciones y Estudios Superiores en Antropología Social.

OXHORN, Philip. (2011), "Beyond Neoliberalism? Latin America's New Crossroads", en J. Burdick; P. Oxhorn; R. Kenneth (eds.), Beyond Neoliberalism in Latin America? New York, Palgrave, pp. 217-233.

PARSONS, Talcott; SMELSER, Niels. (1956), Economy and Society. London, Routledge.

. (1968), “On the Concept of Value Commitments". Sociological Inquiry, vol. 38, no 2, pp. $135-160$.

PUTNAM, Robert. (1993), Making Democracy Work. Princeton, Princeton University Press.

RODRÍGUEZ, Darío. (2004), Organizaciones para la Modernización. México, D.F., Universidad Iberoamericana.

SALES, Roberth; BANNWART, Clodomiro. (2015), “O Acordo de Leniência: Una Análise de sua Compatibilidade Constitucional e Legitimidade". Revista de Direito Público, vol. 10, no 3, pp. 31-50.

SCHOR, Miguel. (2006), “Constitutionalism through the Looking Glass of Latin America". Texas International Law Journal, vol. 41, no 1, pp. 1-37.

SCHROER, Markus. (2006), Räume, Orte, Grenzen. Frankfurt, Suhrkamp.

SIAVELIS, Peter. (2006), "Accomodating Informal Institutions and Chilean Democracy”, en G. Helmke; S. Levitsky (eds.), Informal Institutions and Democracy. Baltimore, The Johns Hopkins University Press, pp. 33-55.

DADOS - Revista de Ciências Sociais, Rio de Janeiro, vol. 59, nº 3, 2016 
SILVA TELLES, Vera da. (2009), "Ilegalismos Urbanos e a Cidade”. Novos Estudos, no 84, pp. 153-173.

. (2013), "Prospectando a Cidade a partir de suas Margens: Notas Inconclusas sobre uma Experiência Etnográfica". Contemporânea, vol. 3, no 2, pp. 359-373.

; VELOSO HIRATA, Daniel. (2007), “Cidade e Práticas Urbanas: Nas Fronteiras Incertas entre o Ilegal, o Informal e o Ilícito". Estudos Avançados, vol. 21, no 61, pp. 173-191.

SIMMEL, George. (1992), Soziologie. Frankfurt, Suhrkamp.

SMITH, Adam. (2004), The Theory of Moral Sentiments. Cambridge, Cambridge University Press.

STAMFORD DA SILVA, Artur. (2012), “Decisión Judicial y Cambios Sociales en la Óptica de la Teoría de Sistemas de Sentido", en C. Hugo; A. Mascareño; A. Urquiza (eds.), Niklas Luhmann y el Legado Universalista de su Teoría. Santiago, RIL, pp. 297-315.

(2016), “Teoria Reflexiva da Decisão Jurídica: Direito, Mudança Social e Movimentos Sociais". Revista de Direito da Universidade de Brasília, vol. 2, no 1, pp. 27-52.

STICHWEH, Rudolf. (2005), Inklusion und Exklusion. Bielefeld, transcript Verlag.

STOKES, Susan. (2001), Mandates and Democracies: Neoliberalism by Surprise in Latin America. New York, Cambridge University Press.

TEUBNER, Gunther. (2012), Constitutional Fragments. Oxford, Oxford University Press.

USLANER, Eric. (2008), Corruption, Inequality, and the Rule of Law. Cambridge, Cambridge University Press.

VALLADARES, Licia. (2000), "A Gênese da Favela Carioca: A Produção Anterior às Ciências Sociais". Revista Brasileira de Ciências Sociais, vol. 15, no 44, pp. 5-32.

. (2005), A Invenção da Favela: Do Mito de Origem à Favela. Rio de Janeiro, FGV Editora.

VACILOTTO, Elisa. (2015), O Uso da Metáfora para Contar a Corrupção: Comparação entre Exemplos de Linguagem Jornalística Italiana e Brasileira. Tesi di Laurea (Magistrale in Lingue Moderne per la Comunicazione e la Cooperazione Internazionale). Università degli Studi di Padova, Italia.

VÉLIZ, Claudio. (1995), The New World of the Gothic Fox. Culture and Economy in English and Spanish America. Berkeley, University of California Press.

VRDOLJAK, Ana. (2013), The Cultural Dimension of Human Rights. Oxford, Oxford University Press.

WEICK, Karl. (1976), “Educational Organizations as Loosely Coupled Systems". Administrative Science Quarterly, vol. 21, no 1, pp. 1-19.

WHITE, Harrison. (2008), Identity and Control. Princeton, Princeton University Press.

WIARDA, Howard; KLINE, Harvey. (1996), Latin American Politics and Development. Boulder, CO, Westview Press. 


\section{RESUMO}

Redes Informais e Instituições Democráticas na América Latina

O artigo propõe três tipos de relações entre instituições processuais baseadas em direitos fundamentais e redes informais na América Latina: uma relação de integração que inicialmente dá suporte a objetivos institucionais, embora os enfraqueça no longo prazo; uma relação de sobreposição que intervém e utiliza de modo parasitário as instituições processuais; e uma relação de dissociação que supõe um deslocamento de instituições processuais dos espaços sociais controlados por redes informais. Metodologicamente, ilustramos este argumento com casos extraídos da literatura e reinterpretados à luz das propostas conceituais presentes no artigo. A conclusão central é que as redes informais geram uma forte propensão à ação contrária ao tipo de ordem social que promovem os direitos fundamentais.

Palavras-chave: redes informais; direitos fundamentais; instituições democráticas; América Latina; normas sociais

\section{ABSTRACT \\ Informal Networks and Democratic Institutions in Latin America}

This article proposes three types of relationship between procedural institutions based on fundamental rights and informal networks in Latin America: a relationship of integration that initially supports institutional objectives before debilitating them in the long run; a relationship of overlap that intervenes and parasitically feeds off procedural institutions; and a relationship of decoupling that involves procedural institutions' displacement from the social spaces controlled by informal networks. Methodologically, we illustrate this argument with cases extracted from literature and reinterpreted in light of the conceptual proposals present in the article. The central conclusion is that informal networks generate a strong impetus towards action that contrasts with the type of the social order promoted by fundamental rights.

Key words: informal networks; fundamental rights; democratic institutions; Latin America; social norms 


\author{
RÉSUMÉ \\ Réseaux Informels et Institutions Démocratiques en Amérique latine
}

Cet article propose trois types de relations entre institutions procédurales basées sur les droits fondamentaux et les réseaux informels en Amérique latine: une relation d'intégration qui s'appuie initialement sur les objectifs institutionnels, mais qui, à long terme, finit par les affaiblir; une relation de superposition qui intervient en faisant un usage parasitaire des institutions procédurales ; et une relation de désaccouplement qui suppose une sortie des institutions procédurales des espaces sociaux contrôlés par des réseaux informels. Méthodologiquement, nous avons illustré cet argument avec des cas extraits de la littérature du domaine et réinterprétés à la lumière des propositions conceptuelles présentes dans l'article. La principale conclusion en est que les réseaux informels génèrent une forte motivation à mener des actions contraires au type d'ordre social promu par les droits fondamentaux.

Mots-clés: réseaux informels; droits fondamentaux; institutions démocratiques; Amérique Latine; normes sociales

\title{
RESUMEN \\ Redes Informales e Instituciones Democráticas en América Latina
}

El artículo propone tres tipos de relación entre instituciones procedimentales basadas en derechos fundamentales y redes informales en América Latina: una relación de integración que inicialmente apoya los objetivos institucionales pero que los debilita en el largo plazo; una relación de superposición que interviene y utiliza parasitariamente las instituciones procedimentales; y una relación de desacoplamiento que supone un desplazamiento de instituciones procedimentales de los espacios sociales controlados por redes informales. Metodológicamente, ilustramos este argumento con casos extraídos de la literatura y reinterpretados a la luz de las propuestas conceptuales presentes en el artículo. La conclusión central es que las redes informales generan una fuerte motivación para la acción contraria al tipo de orden social que promueven los derechos fundamentales.

Palabras clave: redes informales; derechos fundamentales; instituciones democráticas; América Latina; normas sociales 